\title{
Diabetic Glomerulopathy in the Uninephrectomized Rat Resists Amelioration Following Islet Transplantation
}

\author{
M.W.Steffes, R. L.Vernier, D. M. Brown, J. M. Basgen, and S. M. Mauer \\ Departments of Laboratory Medicine and Pathology and Pediatrics, University of Minnesota Medical School, Minneapolis, \\ Minnesota, USA
}

\begin{abstract}
Summary. Uninephrectomy is known to accelerate the development of both functional and morphological changes seen with experimental diabetic nephropathy in the rat. The present experiments utilized electron and light microscopic morphometric techniques to assess glomerular basement membrane width and the volumes of the total mesangium and its cellular and matrix components of inbred Lewis rats made diabetic at 6 weeks of age and uninephrectomized 9 days later. Immunofluorescent microscopy was used to evaluate $\mathrm{IgG}$ and $\mathrm{C}_{3}$ in the mesangium. The reversibility of established diabetic glomerular lesions in uninephrectomized diabetic rats after 7 months of diabetes was studied by performing intraportal transplant of neonatal pancreatic tissue. Renal biopsies were taken 2 months later in transplanted and non-transplanted animals. Islet transplantation lowered plasma glucose to normal levels (29.6 to $7.3 \mathrm{mmol} / \mathrm{l})$ and raised plasma insulin values $(6.3$ to $53 \mu \mathrm{U} / 1)$. Glomerular basement membrane width in transplanted rats
\end{abstract}

$(268 \mathrm{~nm})$ still exceeded the same measure $(226 \mathrm{~nm})$ in nondiabetic uninephrectomized rats. In transplanted animals volumes of the mesangium $\left(0.51 \times 10^{6} \mu \mathrm{m}^{3}\right)$ and of its cellular $\left(0.27 \times 10^{6} \mu \mathrm{m}^{3}\right)$ and matrix $\left(0.24 \times 10^{6} \mu \mathrm{m}^{3}\right)$ components remained higher than similar measures in control rats $(0.32 \times$ $10^{6}, 0.17 \times 10^{6}$ and $0.15 \times 10^{6} \mu \mathrm{m}^{3}$, respectively). Mesangial $\mathrm{IgG}$ in treated animals approached normal, but mesangial $\mathrm{C}_{3}$ remained similar to levels in non-transplanted diabetic control animals. These observations in uninephrectomized-diabetic rats contrast with previous observations in intact diabetic rats in which mesangial volumes and localization of immunoglobulins and complement returned to normal levels following islet transplantation.

Key words: Diabetes, uninephrectomy, islet transplantation, glomerulus, mesangium, basement membrane.

We have shown previously, in rats diabetic for 7 months, that successful islet transplantation results in reversal of established glomerular lesions including increased volume of the mesangium and mesangial immunoglobulin and complement localization [8, 9]. Furthermore, although glomerular basement membrane (GBM) thickening persists following islet transplantation [10], the increased urinary albumin excretion of diabetic rats returns to normal [11].

In the present studies, we examined the effect of islet transplantation on the accelerated diabetic glomerulopathy of uninephrectomized diabetic rats.

\section{Methods}

\section{Animals}

Inbred male Lewis rats (Simonsen Laboratories, Gilroy, California, USA) were made diabetic at 44 days of age with $65 \mathrm{mg} / \mathrm{kg}$ of streptozotocin (a gift of Upjohn, Kalamazoo, Michigan, USA) [9]. Diabetes was confirmed by the development of persistent, non-fasting plasma glukidney. 
Table 1. Body weight, plasma glucose and insulin levels, glomerular basement membrane (GBM) width and mean glomerular volume at 2 months following islet transplantation in uninephrectomized and diabetic rats

\begin{tabular}{|c|c|c|c|c|c|c|c|c|c|}
\hline & $\begin{array}{l}\text { Weight } \\
\text { (g) }\end{array}$ & & $\begin{array}{l}\text { Glucose } \\
\text { (mmol/1 }\end{array}$ & & $\begin{array}{l}\text { Insulin } \\
\mathrm{mU} / \mathrm{l}\end{array}$ & & $\begin{array}{l}\text { GBM width } \\
(\mathrm{nm})\end{array}$ & & $\begin{array}{l}\text { Glomerular volume } \\
\left(\mu \mathrm{m}^{3} \times 10^{6}\right)\end{array}$ \\
\hline \multirow{2}{*}{$\begin{array}{l}\text { Uninephrectomy } \\
\qquad(n=5)\end{array}$} & $426 \pm 64$ & & $7.3 \pm 0.1$ & 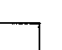 & $102 \pm 34$ & & $226 \pm 4.3$ & & $2.61 \pm 0.33$ \\
\hline & $p<0.001$ & & $p<0.001$ & & $p<0.005$ & & $p<0.001$ & & $p<0.05$ \\
\hline \multirow{2}{*}{$\begin{array}{l}\text { Uninephrectomy- } \\
\text { diabetes }(n=8)\end{array}$} & $198 \pm 28$ & & $29.6 \pm 2.6$ & & $6.3 \pm 3.3$ & & $274 \pm 20$ & & $3.04 \pm 0.37$ \\
\hline & $p<0.001$ & $p<0.01$ & $p<0.001$ & NS & $p<0.001$ & $p<0.025$ & NS & $p<0.001$ & NS \\
\hline $\begin{array}{l}\text { Uninephrectomy- } \\
\text { diabetes, } \\
\text { transplant }(n=7)\end{array}$ & $282 \pm 28$ & ك- & $7.3 \pm 0.8$ & . & $53 \pm 16$ & - & $268 \pm 20$ & & $2.67 \pm 0.36(n=5)$ \\
\hline
\end{tabular}

Values expressed as mean \pm SD. NS $=$ Not significant. Islets were transplanted after 7 months of diabetes

cose levels in excess of $22 \mathrm{mmol} / \mathrm{l}$ and ranging as high as $46 \mathrm{mmol} / 1$. At 53 days of age, diabetic and untreated age-matched control rats were uninephrectomized. Seven months after induction of diabetes, a group of the uninephrectomized-diabetic rats received an intraportal transplant of neonatal pancreatic tissue [12]. Morphological studies were performed on renal biopsies obtained at the time of transplant ( 7 months after streptozotocin administration) and 2 months later (9 months after streptozotocin administration) from the following groups of animals: (a) uninephrectomized-diabetes, non-transplanted; (b) uninephrectomized-diabetes, transplanted; and (c) uninephrectomized-control, non-diabetic. For clarity, we present, primarily, data from the post-transplant biopsies indicating, when appropriate, differences in the results between the pre- and post-transplant samples. All animals were maintained on rat chow and water ad libitum throughout the experiment.

\section{Plasma Measurements}

Glucose was measured by a glucose oxidase method on a Beckman glucose analyzer (Beckman Instruments, Fullerton, California, USA). Insulin was estimated by a double-antibody radioimmunoassay with the first antibody raised in a guinea pig. Rat insulin (Novo Industri, Copenhagen, Denmark) was used as the standard. The lower limit of detection was $5 \mathrm{mU} / \mathrm{l}$. The interassay coefficient of variation was $10 \%$.

\section{Preparation of Tissue}

Immediately after procurement, renal tissue for determination of glomerular volume and for immunofluorescent microscopy was snap frozen in isopentane precooled in liquid nitrogen. For electron microscopy, kidney tissue (1-2 mm cubes) was fixed, processed and evaluated as described previously [8] and outlined briefly below.

\section{Immunofluorescent Microscopy}

Freshly cut, frozen sections were stained with monospecific fluorescein-labelled antibodies for rat $\mathrm{IgG}$ and $\mathrm{C}_{3}[9]$. The intensity of mesangial staining was graded blindly on an arbitrary scale of 0 (no immunofluorescence) to $4^{+}$(very bright fluorescence throughout the mesangium).

\section{Qualitative Electron Microscopy}

Tissues compared included those from the uninephrectomized-diabetes, non-transplanted, uninephrectomized-diabetes, transplanted, and uninephrectomized-control, non-diabetic rats and from previously studied age-matched, intact control rats [8]. Photomicrographs were examined blindly by one of the investigators (RLV), and a description of abnormalities seen was recorded.

\section{Quantitative Studies}

Glomerular volume: A Reichert projecting microscope (magnification $\times 540$ ) with a clear acetate sheet containing a series of concentric circles, calibrated in $\mu \mathrm{m}$ and arrayed as described by Saltikov [13] was used to determine mean glomerular diameters. By utilizing the appropriate coefficients and equations, the distribution of glomerular diameters permits estimation of mean glomerular volume for each biopsy [13]. A mean of 107 profiles (range 70-122) was measured in each biopsy.

Fractional and absolute volumes of glomerular components: Ten to 20 random photomicrographs (approximately $\times 20,000$ ) of each glomerulus were obtained by the technique described previously [8]. An 80point grid was placed over each electron micrograph to determine the proportion of points falling on several components of the glomerulus $[14,15]$. A total of at least 2,000 points on two to four glomeruli were evaluated per biopsy specimen (mean, 2,930; range, 2,146-4,412). Points falling on the mesangium were recorded separately for either cellular or matrix components.

The fractional volume for each mesangial component was utilized to determine the calculated volume of the component in an average glomerulus (calculated volume of the component $=$ fractional volume of the component $\times$ mean glomerular volume).

GBM width: The mean harmonic width of the GBM was measured as previously described [10] by utilizing the intercept method of Gundersen [16]. At least 100 intercepts were measured on each biopsy (mean, 144; range, 104-264).

\section{Statistical Evaluation}

Values are expressed as mean \pm SD. Probability was determined utilizing the two-sided Student's t-test, a value of $p<0.05$ being considered significant.

\section{Results}

Within 2 months following islet transplantation, body weights in uninephrectomized-diabetic, transplanted rats reached levels intermediate between those of uninephrectomized and of uninephrectomized-diabetic rats. Plasma glucose levels returned to and remained at normal levels by 10 days; whereas glucose values in untreated uninephrectomized-diabetic rats continued to be markedly elevated (Table 1). Plasma insulin values rose in transplanted rats to levels intermediate between the 
low levels in untreated uninephrectomized-diabetic animals and the normal values in uninephrectomized rats (Table 1).

IgG and $\mathrm{C}_{3}$ in the mesangia of uninephrectomizeddiabetic glomeruli exceeded control levels (Fig.1). Islet transplantation reduced the intensity of IgG nearly to that seen in the mesangium of control rats but had a lesser effect on mesangial $C_{3}$ staining (Fig.1). Neither parameter returned to normal levels.

Islet transplantation did not alter the thickened GBM width of diabetic animals (Table 1). Mean glomerular volume in uninephrectomized-diabetic rats exceeded that in uninephrectomized animals. The same measure in transplanted rats was equal to that of uninephrectomized animals (Table 1). The fractional volumes of the mesangium and of its matrix and cellular components were increased in uninephrectomized-diabetic compared with uninephrectomized glomeruli and remained increased and unchanged in uninephrectomized-diabetic, transplanted glomeruli (Table 2). The calculated volumes of the total mesangium and each of its components were also elevated in uninephrectomizeddiabetic, compared with uninephrectomized glomeruli. These same values in transplanted glomeruli were only slightly less than volumes in uninephrectomized-diabetic glomeruli and, with the exception of the mesangial matrix, exceeded those in uninephrectomized glomeruli (Table 3). These parameters in uninephrectomized-diabetic, transplanted glomeruli at 9 months remained unchanged from the same parameters measured in uni-
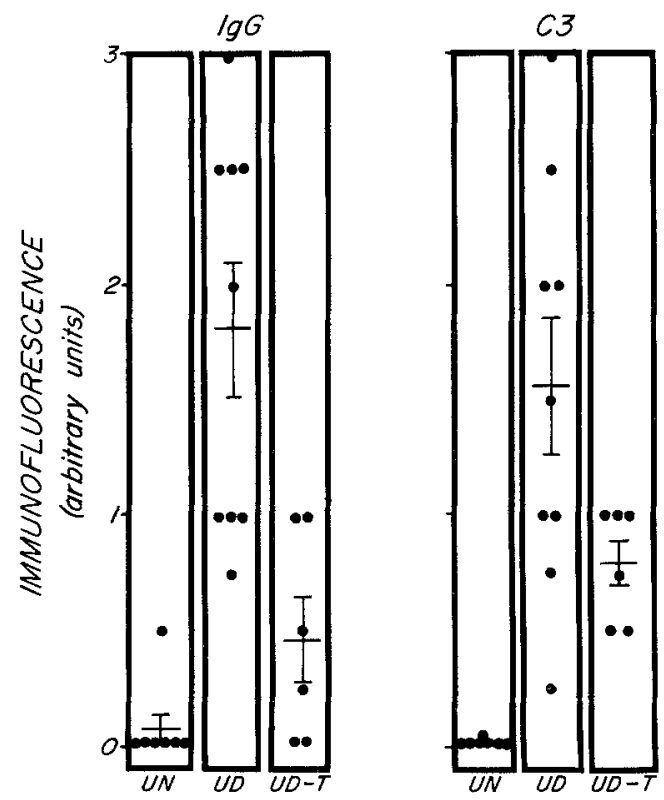

Fig. 1. IgG and $\mathrm{C}_{3}$ in mesangia of non-diabetic uninephrectomized (UN), uninephrectomized-diabetic (UD), and transplanted uninephrectomized diabetic (UD-T) rats after 9 months of diabetes, 2 months post-islet transplantation. Each animal is denoted by a black dot. For each group, mean \pm SEM is noted. Values for IgG in uninephrectomized-diabetic rats exceeded the same measure in either uninephrectomized or uninephrectomized-diabetic, transplanted animals $(p<0.005)$. In contrast, values for $\mathrm{C}_{3}$ in uninephrectomized-diabetic and unineprectomized-diabetic, transplanted animals exceeded levels in control rats $(p<0.001)$. Values for $C_{3}$ in uninephrectomized-diabetic rats exceeded levels in uninephrectomized-diabetic, transplanted animals $(p<0.05)$

Table 2. Fractional volumes (expressed as percentages of total glomerular volume) of mesangial components at 2 months following islet transplantation in uninephrectomized and diabetic rats

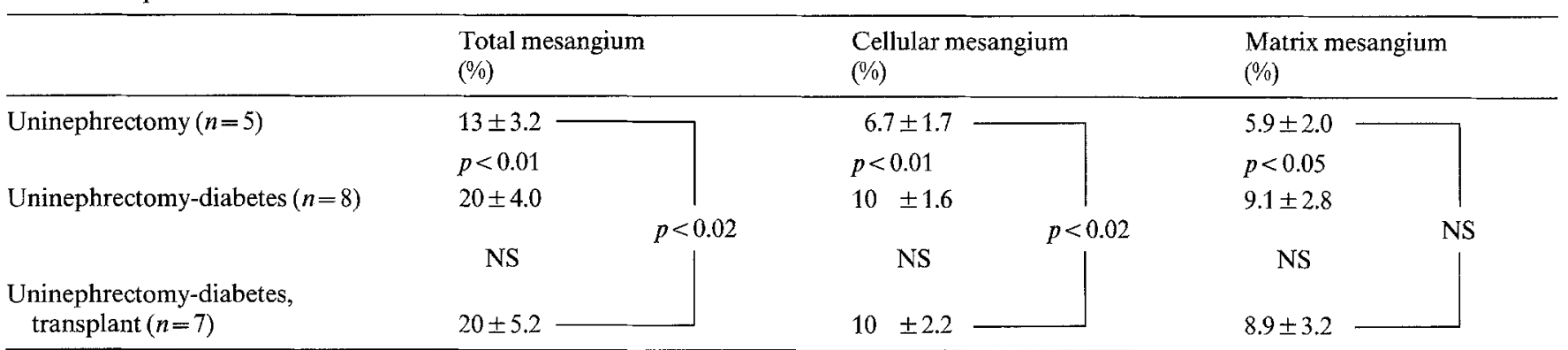

Values expressed as mean $\pm \mathrm{SD}$. NS $=$ Not significant

Table 3. Volume of the mesangium and its subsections at 2 months following islet transplantation in uninephrectomized and diabetic rats

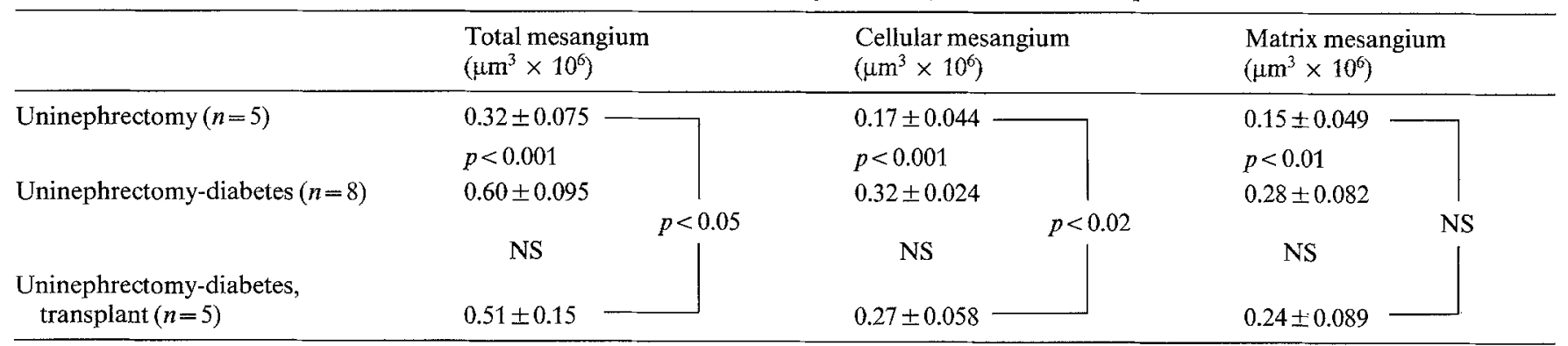

Values expressed as mean $\pm \mathrm{SD} . \quad \mathrm{NS}=$ Not significant 

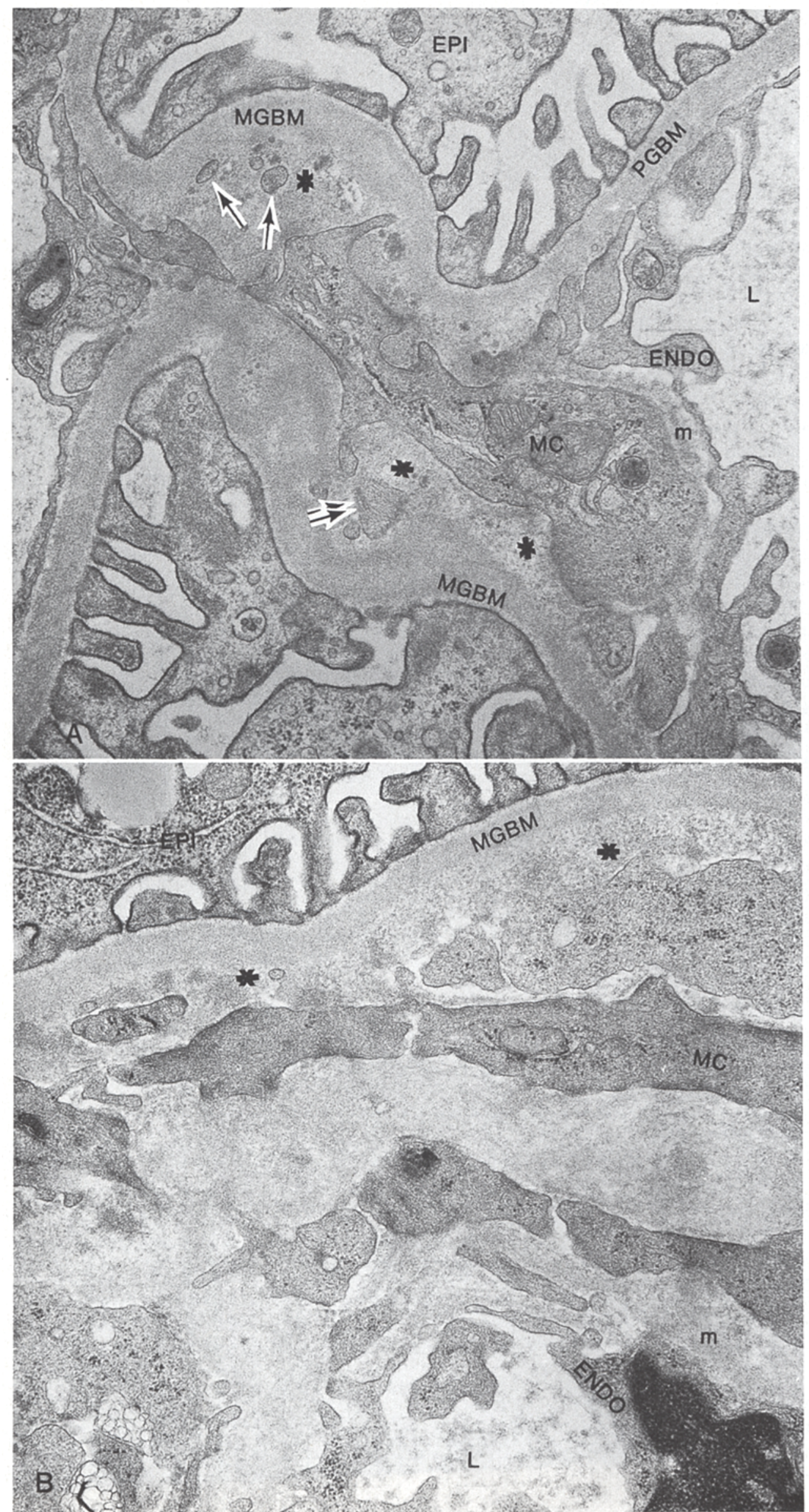

Fig. 2 A. Representative electron micrograph of the mesangial region of the glomerulus from a uninephrectomized (control) rat at 9 months following uninephrectomy $(\times 21000)$. The peripheral glomerular basement membrane (PGBM) has a normal homogeneous structure. The mesangial matrix (*) adjacent to the mesangial GBM (MGBM) is composed primarily of fine fibrils and granules. Small, ovoid membrane-lined structures containing fine granules $(\uparrow)$ or filaments $(\uparrow \uparrow)$ are scattered throughout the loosely organized paramesangial matrix and may represent extensions of mesangial cells. Anarrow mesangial matrix channel (m), adjacent to the endothelium (ENDO) contains loosely organized matrix material. $\mathrm{MC}=$ mesangial cell cytoplasm, EPI = epithelial cell, $\mathrm{L}=$ lumen

B A similar region from a uninephrectomized-diabetic rat, 9 months after nephrectomy and onset of diabetes $(\times 30,000)$. The mesangial GBM

(MGBM) and mesangial matrix (*) adjacent to the mesangial GBM have a similar appearance to that region shown in Figure $2 \mathrm{~A}$, but the quantity of matrix has increased. The total mesangial area is enlarged due to an increase in the amount of both mesangial cytoplasm (MC) and mesangial matrix material $(\mathrm{m})$. The mesangial cell cytoplasm consists of elongated processes and numerous small segments separated from one another by the expanded basement membrane-like mesangial matrix. EPI $=$ epithelial cell, $\mathrm{ENDO}=$ endothelial cell, $\mathrm{L}=$ capillary lumen. 
Table 4. Glomerular basement membrane (GBM) width, albuminuria and the volumes of mesangium and of its components in intact and uninephrectomized diabetic rats (after 9 months of diabetes and 2 months post islet transplantation)

\begin{tabular}{|c|c|c|c|c|c|}
\hline & $\begin{array}{l}\text { GBM width } \\
\text { (nm) }\end{array}$ & $\begin{array}{l}\text { Albuminuria } \\
\text { (mg/24 hr } / 100 \mathrm{~g} \\
\text { body weight) }\end{array}$ & $\begin{array}{l}\text { Mesangium } \\
\left(\mu \mathrm{m}^{3} \times 10^{6}\right)\end{array}$ & $\begin{array}{l}\text { Cells } \\
\left(\mu \mathrm{m}^{3} \times 10^{6}\right)\end{array}$ & $\begin{array}{l}\text { Matrix } \\
\left(\mu \mathrm{m}^{3} \times 10^{6}\right)\end{array}$ \\
\hline \multicolumn{6}{|l|}{ Control rats } \\
\hline Intact & $\begin{array}{c}222 \pm 16(5) \\
\text { NS }\end{array}$ & $\begin{array}{l}0.05 \pm 0.02(5) \\
p=0.008\end{array}$ & $\begin{array}{c}0.24 \pm 0.06(4) \\
\mathrm{NS}\end{array}$ & $\begin{array}{c}0.14 \pm 0.04(4) \\
\text { NS }\end{array}$ & $\begin{array}{c}0.10 \pm 0.03(4) \\
\mathrm{NS}\end{array}$ \\
\hline Uninephrectomized & $226 \pm 4.3(5)$ & $3.3 \pm 2.8(4)$ & $0.32 \pm 0.08(5)$ & $0.17 \pm 0.04(5)$ & $0.15 \pm 0.05(5)$ \\
\hline & NS & $p<0.001$ & $\mathrm{p}<0.001$ & $\mathrm{p}<0.001$ & NS \\
\hline Uninephrectomized & $274 \pm 20(8)$ & $10.0 \pm 8.0(6)$ & $0.60 \pm 0.10(8)$ & $0.32 \pm 0.02(8)$ & $0.28 \pm 0.08(8)$ \\
\hline \multicolumn{6}{|l|}{ Diabetic transplanted rats } \\
\hline Intact & $\begin{array}{c}249 \pm 20(8) \\
\text { NS }\end{array}$ & $\begin{array}{l}0.12 \pm 0.11(9) \\
p<0.001\end{array}$ & $\begin{array}{l}0.26 \pm 0.08(9) \\
p<0.005\end{array}$ & $\begin{array}{l}0.14 \pm 0.05(9) \\
p<0.005\end{array}$ & $\begin{array}{l}0.12 \pm 0.03(9) \\
p<0.05\end{array}$ \\
\hline Uninephrectomized & $268 \pm 20(7)$ & $1.5 \pm 1.2(7)$ & $0.51 \pm 0.15(5)$ & $0.27 \pm 0.06(5)$ & $0.24 \pm 0.09(5)$ \\
\hline
\end{tabular}

Values expressed as mean \pm SD (number of animals). NS $=$ Not significant. All comparisons, except for albuminuria, were made with the Student's two-tailed t-test: $p$ values for albuminuria determined by rank sum test. Data taken from this study and from previous work $[8,10,11]$.

nephrectomized-diabetic glomeruli at 7 months. The enlarged calculated volumes of the total mesangium in uninephrectomized-diabetic glomeruli reflected equal contributions of both cellular and matrix components, which nearly doubled values in uninephrectomized glomeruli (Table 3).

The qualitative morphological changes in the mesangium of uninephrectomized, uninephrectomized-diabetic and uninephrectomized-diabetic, transplanted rats correlated with the quantitative morphometric findings. The typical mesangial region in glomeruli of uninephrectomized rats consisted of one or two mesangial cell nuclei and associated contiguous cytoplasm, separated by a few narrow bands of fibrillar matrix which rarely exceeded $100 \mathrm{~nm}$ in width and were similar in relative quantity and quality to the matrix material in normal rat glomeruli. In uninephrectomized rats there appeared to be an increase in the quantity of matrix material located beneath the mesangial GBM (Fig. $2 \mathrm{~A}$ ). In addition to an increase in width, the matrix in this area was less compact and more mottled than normal and contained numerous irregular small electron dense particles and fibrils of variable density. In favourable cross-sections, numerous fine granules (approximately $10 \mathrm{~nm}$ ) were visible within ovoid bodies that likely represented crosssections of cytoplasmic extensions (Fig. 2 A). Tangential sections suggested that the granules in the bodies were cross-sections of fibrils.

The mesangial cytoplasm of both uninephrectomized-diabetic and uninephrectomized-diabetic, transplanted rats was segmented into small irregular cytoplasmic masses by numerous interconnected broad bands of loosely packed, mottled matrix material (Fig. 2B). In addition, the widened and mottled matrix material beneath the mesangial GBM was similar to that described in uninephrectomized rats but was present in greater amounts in that location and throughout the mesangium of both diabetic and transplanted rats.

\section{Discussion}

The present studies extend our earlier light microscopic observations of the glomerulus in uninephrectomizeddiabetic rats [6]. Specifically, the increased mesangial volume in uninephrectomized-diabetic compared with diabetic glomeruli resulted primarily from expansion of the mesangial cell component (Table 4). Although statistically not significant, an expanded mesangial matrix volume also contributed to the enlarged mesangial volume of uninephrectomized-diabetic rats. The mechanisms underlying the accelerated mesangial lesions remain unclear. Yet, as previously hypothesised [6], these processes probably reflect alterations in glomerular haemodynamics consequent to uninephrectomy which augment the effects of the metabolic abnormalities of diabetes and the altered glomerular haemodynamics of the diabetic state. In comparing the present results with those previously found in intact rats [10] no influence of uninephrectomy on GBM thickness was observed in either diabetic or non-diabetic animals. However, the present studies in uninephrectomized-diabetic rats confirm the development of GBM thickening noted previously by us and by others in intact diabetic rats $[10,17]$ (Table 4).

The failure of pancreatic transplantation to affect substantially mesangial structure in uninephrectomizeddiabetic rats eludes easy explanation. A longer period of observation following islet transplantation in uninephrectomized-diabetic rats may demonstrate greater effects. Yet, within time periods identical to those of the present study, intact diabetic rats responded to amelioration of the diabetic state by a reduction both in mesangial matrix and cellular volumes (Table 4). Since the matrix increase predominates as the structural change in mesangium of intact diabetic rats, the reversal of this abnormality becomes not surprisingly the major factor in the return of total mesangial volume to normal values fol- 
lowing pancreatic transplantation in those animals [8]. In the uninephrectomized-diabetic rat the increased cellular volume (Table 4) may reflect changes in mesangial cell structure or function which have progressed beyond reversibility by islet transplantation.

In 1966 Kimmelstiel [18] recognized that the increased mesangial volume observed early in diabetic nephropathy in man resulted primarily from an increase in the 'quantity of bars in the spongy mesangial matrix'. He stated that with progression the electron density of the bars increased and the fibrillar (granular) architecture became obscured. He concluded that 'the fundamental change in both nodular and diffuse glomerulosclerosis is the same, namely an increase of basement membrane-like material in the mesangium with secondary encroachment upon and thickening of the peripheral basement membranes' [18]. Since thickening of the peripheral GBM and an increase in mesangial matrix were both present in diabetic patients of $1 \frac{1 / 2}{-5}$ years duration, Østerby [19] considered as untenable the concept that mesangial hyperplasia causes peripheral GBM thickening. Nevertheless, it seems clear that functional and morphological abnormalities of the mesangium are important early and late [20] events in the pathogenesis of diabetic nephropathy in man.

Østerby [21] and Rasch [22] have emphasized the prominence of matrix material which accumulates beneath the mesangial GBM in both diabetic people and rats. Control of blood glucose to normal levels in the diabetic rat prevented these changes [22]. The mesangium can take up and process circulating macromolecules [23]. Lee and Vernier [24] have shown by an immuno-peroxidase technique that the sub-basement membrane region of the mesangial matrix was the predominant site of localization of injected aggregated human albumin in the glomeruli of mice. Further we have reported that those mesangial areas most thickened secondary to diabetes have the greatest disturbance in the removal of macromolecules localized therein [25]. The present studies show that increased mesangial immunoglobulin and complement localization in uninephrectomized-diabetic rats was much less affected by islet transplantation than noted previously in intact diabetic rats [9]. One may hypothesise that the structural alterations of the mesangium in diabetes, accentuated by uninephrectomy, have led to functional changes which are relatively irreversible. Alternatively, the glomerular haemodynamic abnormalities resulting from uninephrectomy may cause persistent mesangial changes despite cure of the diabetic state. This alternative seems less likely since uninephrectomy per se produced no mesangial pathology in the time scale of the present studies.

The present experiments support the concept that the haemodynamic state of the glomerulus influences the rate at which diabetic glomerular lesions develop. They suggest that more advanced diabetic glomerulopathy in rats is resistant to reversal by successful islet transplanta- tion. These studies, by demonstrating GBM thickening following islet transplantation, reinforce the dichotomy between albuminuria and this structural parameter [11].

Acknowledgements. We thank M.Stahlmann for technical assistance, M. Hoff for graphical work and R. Esslinger for editorial advice. This work was supported by grants from the National Institutes of Health (AM 17697 and HL 23749) and the American Diabetes Association, Minnesota Affiliate. The work was completed during the tenure of a Fogarty Senior International Fellowship awarded to M. W. Steffes.

\section{References}

1. Azar S, Johnson MA, Hertel B, Tobian L (1977) Single-nephron pressures, flows and resistances in hypertensive kidneys with nephrosclerosis. Kidney Int 12: $28-40$

2. Peters $G$ (1978) Introduction: history and problems of compensatory adaptation of renal functions and of compensatory hypertrophy of the kidney. Yale J Biol Med 51: 235-245 (International Symposium on Renal Adaptation to Nephron Loss, Montreux, Switzerland. Neale Watson Academic Publications, New York)

3. Mogensen CE (1976) Renal function changes in diabetes. Diabetes 25: 872-879

4. Seyer-Hansen K, Hansen J, Gundersen HJG (1980) Renal hypertrophy in experimental diabetes. A morphometric study. Diabetologia 18: 501-505

5. Hostetter TH, Troy JL, Brenner BM (1981) Glomerular hemodynamics in experimental diabetes mellitus. Kidney Int 19:410-415

6. Steffes MW, Brown DM, Mauer SM (1978) Diabetic glomerulopathy following unilateral nephrectomy in the rat. Diabetes 27:35-41

7. Mauer SM, Steffes MW, Azar S, Sandberg SK, Brown DM (1978) The effects of Goldblatt hypertension on the development of glomerular lesions of diabetes mellitus in the rat. Diabetes 27:738-744

8. Steffes MW, Brown DM, Basgen JM, Mauer SM (1980) Amelioration of mesangial volume and surface alterations following islet transplantation in diabetic rats. Diabetes 29:509-515

9. Mauer SM, Sutherland DER, Steffes MW, Leonard RJ, Najarian JS, Michael AF, Brown DM (1974) Pancreatic islet transplantation: effects on the glomerular lesions of experimental diabetes in the rat. Diabetes 23: 748-753

10. Steffes MW, Brown DM, Basgen JM, Matas AJ, Mauer SM (1979) Glomerular basement membrane thickness following islet transplantation in the rat. Lab Invest 41:116-118

11. Mauer SM, Brown DM, Matas AJ, Steffes MW (1978) Effects of pancreatic islet transplantation upon the increased urinary albumin excretion rates in intact and uninephrectomized rats with diabetes mellitus. Diabetes 27:959-964

12. Matas AJ, Payne WD, Grotting JC, Sutherland DER, Steffes MW, Hertel BF, Najarian JS (1977) Portal versus systemic transplantation of dispersed neonatal pancreas. Transplantation 24: 333-337

13. Saltikov SA (1967) The determination of the size distribution of particles in an opaque material from a measurement of the size distribution of their sections. In: Elias H (ed) Stereology. SpringerVerlag, Berlin, pp 163-173

14. Gundersen HJG, Østerby R (1978) Sampling problems in the kidney. In: Miles RE, Serra J (eds) Lecture notes in biomathematics, vol 23, Geometrical probability and biological structures: Buffon's 200th Anniversary Proceedings, Paris 1977. Springer-Verlag, New York, pp 185-191

15. Weibel ER, Bolender RP (1973) Stereological techniques for electron microscopic morphometry. In: Hayat MA (ed) Principles and techniques of electron microscopy, biological applications, vol 3. Van Nostrand Reinhold, New York, pp 237-296

16. Gundersen HJG (1980) Stereology - or how figures for spatial shape and content are obtained by observation of structures in sections. Microse Acta 83: 409-426

17. Rasch R (1979) Prevention of diabetic glomerulopathy in streptozo- 
tocin diabetic rats by insulin treatment. Glomerular basement membrane thickness. Diabetologia 16:319-323

18. Kimmelstiel P(1966) Diabetic nephropathy. In: Mostofi FK, Smith DE (eds) The Kidney. International Academy of Pathology Monograph No 6, Williams and Wilkins, Baltimore, pp 226-236

19. Østerby R (1972) The number of glomerular cells and substructures in early juvenile diabetes. A quantitative electron microscopic study. Acta Path Microbiol Scand 80:785-800

20. Gundersen HJG, Østerby R (1977) Glomerular size and structure in diabetes mellitus. II. Late abnormalities. Diabetologia 13:43-48

21. Østerby R (1975) Early phases in the development of diabetic glomerulopathy. Acta Med Scand 574 (Suppl): 1-80

22. Rasch R (1979) Prevention of diabetic glomerulopathy in streptozotocin diabetic rats by insulin treatment. The mesangial regions. Diabetologia 17: 243-248

23. Mauer SM, Shvil Y (1979) The glomerular mesangium. In: Black Sir D, Jones NF (eds) Renal disease. Blackwell Scientific Publications, Oxford, pp 93-106
24. Lee S, Vernier RL (1980) Immunoelectron microscopy of the glomerular mesangial uptake and transport of aggregated human albumin in the mouse. Lab Invest $42: 44-58$

25. Mauer SM, Steffes MW, Chern M, Brown DM (1979) Mesangial uptake and processing of macromolecules in rats with diabetes mellitus. Lab Invest 41:401-406

Received: 2 November 1981

and in revised form: 24 March 1982

Dr. Michael W.Steffes

Department of Laboratory Medicine and Pathology

Box 198 Mayo Building' University of Minnesota

Minneapolis,

Minnesota 55455, USA 